\title{
Aplikasi Penilaian Lomba Burung Murai Batu Berbasis Android
}

\author{
Lucky Febrian, Buhori Muslim \& Debi Gusmaliza \\ Sekolah Tinggi Teknologi Pagar Alam \\ Email: debigusmaliza@gmail.com
}

\begin{abstract}
This research aims to design and build an Android-based Magpie Batu race evaluation app. The appraisal application is one of the media used in the judging process for judges to participants in the bird competition. Based on the results of observations on Saturday Saturday's cheerful contest. It was found that the current system was still manual using paper, pen and flag media to determine the results of the race and the process the calculation of the value after the end time is also still manually with counting the total number of values obtained can only be known which bird won, so it was less effective in the assessment of the Magpie Stone race. The system development method in this application uses the Luther method which consists of several stages, namely concept, design, material collecting, assembly, testing, distribution. To measure the success of this application, alpha testing is done to test the validity of the product to design experts, material experts, linguists and media experts. The results expected in this study are in the form of an Android-based appraisal of the Magpie Stone contest as a media for the Magpie Stone race in Pagar Alam City.
\end{abstract}

Keywords: application, appraisal, android, competition, luther, testing

\section{Pendahuluan}

Perkembangan teknologi informasi setiap hari meningkat dengan pesat dan luas, seiring dengan perkembangan teknologi komputer yang terus meningkat dalam hitungan hari. Bahkan hampir semua instansi baik itu instansi pemerintah dan swasta telah memanfaatkan pengembangan teknologi untuk meningkatkan sistem manajemen dan kinerjanya salah satunya menggunakan media internet. Dengan memanfaatkan telepon pintar, aplikasi ini akan dijalankan di perangkat mobile berbasis Android (Adithya Marhaendra Kusuma, APLIKASI BUKU DIGITAL BIDANG TEKNOLOGI INFORMASI, 2016).

Pada saat perilisan perdana Android 5 November 2007, Android bersama Open Handsse Alliance menyatakan mendukung pengembangan Open Source pada perangkat Mobile. Di lain pihak, Google meliris kode-kode Android di bawah lisensi Apche, sebuah lisensi perangkat lunak dan open platform perangkat seluler. Di dunia ini terdapat dua jenis distributor sistem operasi Android. Pertama yang mendapat dukungan penuh dari Google atau Google mail services (GMS) dan kedua adalah yang benar-benar bebas distribusinya tanpa dukungan langsung Google atau dikenal sebagai Open Handset Distribution (OHD). Tidak hanya menjadi sistem operasi di Smartphone, saat ini Android menjadi pesaing utama dari Apple pada saat operasi Table PC. Pesatnya pertumbuhan Android itu sendiri adalah Platform yang sangat lengkap baik itu sistem operasinnya, Aplikasi dan tool pengembangan, Market aplikasi Android serta dukungan yang tinggi dari komunitas Open Source di dunia, sehingga android terus berkembang pesat baik dari segi

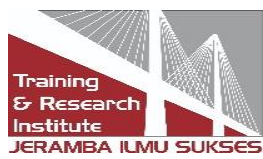


teknologi maupun dari segi jumlah device yang ada didunia (Sari, 2014) Android merupakan sistem operasi yang dikembangkan untuk perangkat mobile berbasis Linux. Pada awalnya sistem operasi ini dikembangkan oleh Android Inc. yang kemudian dibeli oleh Google pada tahun 2005. Dalam usaha mengembangkan Android, pada tahun 2007 dibentuklah Open Handset Alliance (OHA), sebuah konsorsium dari beberapa perusahaan, yaitu Texas Instruments, Broadcom Corporation, Google, HTC, Intel, LG, Marvell Technology Group, Motorola, Nvidia, Qualcomm, Samsung Electronics, Sprint Nextel, dan T-Mobile dengan tujuan untuk mengembangkan standar terbuka untuk perangkat mobile dengan menggunakan aplikasi (Maiyana, 2018).

Aplikasi dapat diartikan sebagai pemecahan masalah yang menggunakan salah satu teknik pemrosesan data aplikasi yang biasanya berpacu pada sebuah komputansi yang diinginkan atau diharapkan. Aplikasi biasanya berupa perangkat lunak yang berbentuk software yang berisi kesatuan perintah atau program yang dibuat untuk melaksanakan sebuah pekerjaan yang diinginkan. Aplikasi dapat membantu meringankan pekerjaan manusia atau bahkan menggantikan posisi manusia dalam dunia kerja telah beredar secara luas. Salah satu kemajuan teknologi itu yaitu perkembangan multimedia (Putrawansyah, Aplikasi Computer Assisted Test (CAT) Pada Penerimaan Mahasiswa Baru Sekolah Tinggi Teknologi Pagar Alam (STTP), 2017).

Berdasarkan studi menggunakan metode wawancara dengan salah satu juri yang berpengalaman di bidang lomba Burung Murai Batu di kota Pagar Alam. Pada saat penilaian juri memberikan 3 kategori penilaian, 3 kategori tersebut terdiri dari bunyi, stabil bunyi, dan variasi lagu kemudian burung yang memiliki gaya, irama, tembakan, dan volume akan mendapatkan nilai tambah dari bendera merah yang bernilai 100 poin, bendera biru 50 poin serta bendera kuning kuning 10. Dan kordinasi lapangan (Korlap) menilai bunyi saja. Dengan menggunakan kertas dan pena para juri dan korlap menilai burung tersebut membuat kinerja juri kurang efektif dari segi waktu beserta kinerjanya. Penilaian dalam lomba Burung Murai Batu juga belum cukup efisien karena dalam sistem penilaian masih manual dan tingkat kecurangan yang masih bisa dilakukan oleh para juri, misalkan waktu penilaian telah berakhir juri masih bisa memberikan nilai padahal waktu penilaian telah habis. Dan juga dalam sistem yang masih manual lebih membutuhkan waktu yang banyak dan menyebabkan jadwal perlombaan lainnya tidak berjalan sesuai dengan waktu yang telah ditentukan.

Menurut penelitian terdahulu (Yohanes Krisdian, 2015). Dengan judul "APLIKASI LOMBA BURUNG BERBASIS ANDROID" telah dirancang dan dibuat Aplikasi Android yang bertujuan untuk memudahkan dalam penginputan jadwal perlombaan burung, pendaftaran perlombaan burung dan informasi pemenang perlombaan burung berdasarkan perekapan nilai dari juri Perancangan sistem ini menggunakan usecase diagram, class diagram, activity diagram dan sequence diagram Tabel Jadwal, Tabel Lokasi, Tabel Member, Tabel Nama Perlombaan, Tabel Pendaftaran dan Tabel Daftar Peserta. Selanjutnya perancangan input dan output berisi desain Data Login Admin, Desain Menu Utama, Desain Nama Perlombaan, Desain Lokasi Perlombaan, Desain Data Member, Desain Penjadwalan Lomba Burung, Desain

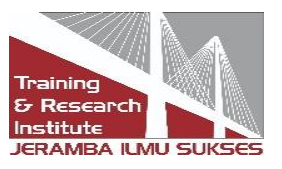


Pendaftaran Lomba Burung, Desain Data Peserta, Desain Laporan Pendapatan Periode, Desain Login User, Desain Daftar Member, Desain Cari Jadwal, Desain Pesan Tiket, Desain Pembatalan Tiket, Desain Cek Status Pembayaran, Desain Bukti Pemesanan Dan Desain Informasi Pemenang Lomba Burung.

Selanjutnya penelitian dari (Ito Riris Immasari, 2017) Dengan judul "APLIKASI INFORMASI KICAU MANIA DEPOK BERBASIS ANDROID” Aplikasi kicau untuk kicau mania yang dibuat menggunakan Android Studio telah di uji coba pada beberapa smartphone dengan sistem operasi Android, dengan batas versi minimal 4.4 yaitu KitKat dan versi maksimal yaitu 7.1.2 atau disebut juga Nougat, aplikasi ini berjalan optimal di ukuran layar 5.0 inchi keatas. Setelah dicoba oleh dua puluh orang user, dapat disimpulkan bahwa $80 \%$ pengguna setuju bahwa lokasi yang diberikan aplikasi ini akurat, 70\% setuju bahwa tips bersifat informatif, $60 \%$ setuju suara dari masteran yang diberikan mempengaruhi burung peliharaan user, 40\% setuju tema dari warna memberikan efek nyaman saat digunakan, dan $90 \%$ user setuju jika aplikasi Bekicau dipublikasikan.

Berdasarkan latar belakang diatas maka peneliti ingin melakukan penelitian dengan judul "Aplikasi Penilaian Lomba Burung Murai Batu Berbasis Android".

\section{Tinjauan Literatur}

Menurut (Safaat, Android pemrograman Aplikasi Mobile Smartphone dan Tablet PC Berbasis Android, 2016) Android adalah aplikasi sistem operasi untuk telpon seluler yang berbasis linux. Android menyediakan platform terbuka bagi para pengembang untuk menciptakan aplikasi mereka sendiri untuk digunakan oleh bermacam piranti bergerak.

Menurut (Murtiwiyati \& Lauren, 2013 ) Android adalah sebuah sistem operasi untuk perangkat mobile berbasis linux yang mencakup sistem operasi, middleware dan aplikasi. Android menyediakan platform terbuka bagi para pengembang untuk menciptakan aplikasi mereka. Awalnya, Google Inc. membeli Android Inc. yang merupakan pendatang baru yang membuat piranti lunak untuk ponsel smartphone. Kemudian untuk mengembangkan Android, dibentuklah Open Handset Alliance, konsorsium dari 34 perusahaan piranti keras, piranti lunak, dan telekomunikasi, termasuk Google, HTC, Intel, Motorola, Qualcomm, T-Mobile, dan Nvidia.

Dalam perkembangan sistem operasi Android dari awal hingga saat ini berbagai versi Android yang telah di rilis, dan telepon pertama yang mengusung Android ini adalah HTC Dream yang launching pada 22 Oktober 2008. Adapun versi-versi Android yang telah dirilis adalah sebagai berikut (Safaat, Android PemrogramanAplikasi Mobile Smartphone dan Tablet Pc Berbasis Android, 2014): Android Versi 1.1, Android Versi 1.5 (Cupcake), Android Versi 1.6 (Donut), Android Versi 2.0/2.1 (Eclair), Android Versi 2.2 (Froyo : Frozen Yoghout), Android versi 2.3 (Gingerbread), Android Versi 3.0/3.1 (Honeycom), Android Versi 4.0 (ICS: Ice Cream Sandwich), Android Versi 4.1 (Jelly Bean), Android Versi 4.4 (KitKat), Android Versi 5.0 (Lolipop), Android Versi 6.0 (Marsmellow), Android Versi 7.0 (Nougat), Android Versi 8.0 (Oreo), Android Versi 9.0 (Pie).

Menurut ( Andriansyah, Fernando, \& Sadikin, 2017 ) Aplikasi adalah penggunaan atau penerapan suatu konsep yang menjadi pokok pembahasan yang dapat diartikan

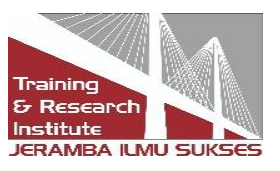


juga sebagai program komputer yang dibuat oleh suatu perusahaan komputer untuk membantu mengerjakan tugas tugas manusia yang terdiri dari beberapa form, report, disusun sedemikian rupa sehingga dapat mengakses data.

Menurut (Rojali Soni Afandi, 2013) Aplikasi mempunyai arti yaitu pemecahan masalah yang menggunakan salah satu tehnik pemrosesan data aplikasi yang biasanya berpacu pada sebuah komputansi yang diinginkan atau di harapkan maupun pemrosessan data yang diharapkan. Aplikasi biasanya berupa perangkat lunak yang berbentuk software yang berisi kesatuan perintah atau program yang dibuat untuk melaksanakan sebuah pekerjaan yang diinginkan.

Basis data adalah kumpulan file-file yang saling berelasi, relasi tersebut biasa ditunjukan dengan kunci ari tiap file yang ada. Satu basis data menunjukan kumpulan data yang dipakai dalam satu lingkup informasi. Dalam satu file terdapat record-record yang sejenis, sama besar, sama bentu, merupakan satu kumpulan entity yang seragam. Satu record terdiri dari field-field yang saling berhubungan untuk menunjukan bahwa field tersebut dalam satu pengertian yang lengkap dan direkam dalam satu record (Rahmad \& Setiady, 2014).

Berikut adalah database yang didukung oleh PHP menurut (Musyawarah, 2005), Database dBase Dengan PHP, Database PostgreSQL dengan PHP, Database Interbase Dengan PHPI, Database Oracle Dengan PHP, Database SQLite Dengan $P H P$, g mendukung bahasa $S Q L$, Database Dengan PHP Melalui ODBC, Database $M y S Q L$ Dengan $P H P$, bisa dikatakan paling cepat, dan jarang bermasalah. $M y S Q L$ telah tersedia juga di lingkungan Windows.

Dalam pembuatan Aplikasi penilaian lomba burung lovebird menggunakan Database MySQL dengan PHP. Tujuan memakai database MySQL dengan PHP karena database-nya bersifat Open Source sehingga dapat digunakan oleh siapapun tanpa dibebani biaya lisensi, MySql mampu menangani data yang cukup besar dan memiliki kecepatan yang stabil.

Menurut (PANGASTUTI, 2013) Penilaian merupakan serangkaian kegiatan untuk memperoleh, menganalisis, dan menafsirkan data tentang proses dan hasil belajar peserta didik yang dilakukan secara sistematis dan berkesinambungan, sehingga menjadi informasi yang bermakna dalam pengambilan keputusan. Penilaian dalam pendidikan adalah keputusan-keputusan yang diambil dalam proses pendidikan secara umum; baik mengenai perencanaan, pengelolaan, proses dan tindak lanjut pendidikan atau yang menyangkut perorangan, kelompok, maupun kelembagaan.

Menurut (Abdullah, 2015) Penilaian (evaluasi) adalah kegiatan mengukur ketercapaian program pendidikan, perencanaan suatu program pendidikan termasuk kurikulum dan pelaksanaannya, pengadaan dan peningkatan kemampuan guru, pengelolaan pendidikan, dan reformasi pendidikan secara menyeluruh.

Menurut (Krisdian \& Nugroho, 2015) Lomba burung merupakan ajang atau rangkaian kegiatan yang dilakukan oleh para penggemar burung guna mengkompetisikan dengan tujuan untuk pembuktian sebagai predikat terbaik. Umumnya lomba burung ini diadakan dalam rangka mengkompetisikan berbagai jenis burung dengan penilaian dari bebrbagai segi aspek. Adapun penilaiannya seperti : irama lagu, volume atau suara dan gaya atau fisik. 
Menurut (Sano \& Muhammad, 2019) Lomba burung merupakan media untuk menunjukkan identitas bagi para Kicau Mania dan merujuk kepada eksistensi para penggemar burung juga. Jadi bisa dikatakan bahwa identitas merupakan bagian dari masyarakat dan individu khususnya. Dari penghargaan yang diperoleh pada perlombaan akhirnya menjadi identitas setiap peserta perlombaan burung. Identitas tersebut yang akhirnya melekat pada diri seorang Kicau Mania. Dari penghargaan identitas tersebut memunculkan stratifikasi sosial di dalam perlombaan kicau mania. Berikut disajikan penelitian sebelumnya:

\begin{tabular}{|c|c|c|c|c|}
\hline No & $\begin{array}{l}\text { Nama } \\
\text { Peneliti }\end{array}$ & Judul & Hasil & $\begin{array}{c}\text { Hubungan Dengan } \\
\text { Penelitian }\end{array}$ \\
\hline 1 & $\begin{array}{l}\text { (Eka } \\
\text { Lasarsati } \\
\text { Amelia, } \\
\text { 2019) }\end{array}$ & $\begin{array}{l}\text { Sistem } \\
\text { Pendukung } \\
\text { Keputusan } \\
\text { Menentukan } \\
\text { Lovebird } \\
\text { Unggul dalam } \\
\text { Perlombaan } \\
\text { Menggunakan } \\
\text { Metode AHP- } \\
\text { Topsis }\end{array}$ & $\begin{array}{l}\text { Dengan adanya sistem pendukung keputusan } \\
\text { menentukan lovebird unggul dalam } \\
\text { perlombaan dengan metode AHP-TOPSIS } \\
\text { peserta bisa lebih melihat transparansi nilai } \\
\text { pada saat perlombaan, karena penilaian } \\
\text { tersebut di tampilkan pada layar } L C D \text { yang } \\
\text { dapat di lihat oleh seluruh peserta lomba. }\end{array}$ & $\begin{array}{l}\text { Hubungan dengan } \\
\text { Penelitian ini yaitu } \\
\text { agar peneliti dapat } \\
\text { membuat aplikasi } \\
\text { agar juri dapat } \\
\text { Menunjang penilaian } \\
\text { yang lebih transparan } \\
\text { pada saat } \\
\text { perlombaan }\end{array}$ \\
\hline 2 & $\begin{array}{l}\text { (Rizal } \\
\text { Rudiantoro, } \\
\text { 2019) }\end{array}$ & $\begin{array}{l}\text { Rekomendasi } \\
\text { Pemilihan } \\
\text { Burung } \\
\text { Menggunakan } \\
\text { Metode } \\
\text { Simple } \\
\text { Additive } \\
\text { Weighting } \\
\text { (SAW) dan } \\
\text { Technique } \\
\text { Order } \\
\text { Preference by } \\
\text { Similarity To } \\
\text { Ideal } \\
\text { Solution } \\
\text { (TOPSIS) }\end{array}$ & $\begin{array}{l}\text { Metode SAW dan TOPSIS dapat } \\
\text { diterapkan pada rekomendasi pemilihan pada } \\
\text { burung berkicau. Hasil untuk mendapatkan } \\
\text { rekomendasi pemilihan burung terbaik dengan } \\
\text { nilai prefensi untuk proses peringkat } \\
\text { berdasarkan nilai tertinggi. Preferensi tertinggi } \\
\text { adalah solusi yang paling optimum berdasarkan } \\
\text { sistem untuk rekomendasi terbaik. Pengujian } \\
\text { memiliki pengaruh terhadap signifikan } \\
\text { keberhasilan sistem dalam } \\
\text { merekomendasi pemilihan burung berkicau. } \\
\text { Pengujian dilakukan dengan perbandingan } \\
\text { peringkat sistem dengan hasil peringkat pakar } \\
\text { untuk mendapatkan koefisien korelasi antara } \\
\text { kedua variabel. Dari hasil yang didapatkan } \\
\text { antara pengujian maka dapat disimpulkan, } \\
\text { metode SAW dan TOPSIS dapat digunakan } \\
\text { dalam merekomendasi pemilihan burung } \\
\text { berkicau dengan hasil yang baik dengan nilai } \\
\text { hasil pengujian Spearman jenis burung love } \\
\text { bird 6,63, cucak hijau 3,46 dan kacer 5,42 } \\
\text { dengan nilai signifikan antara sistem dengan } \\
\text { nilai pakar dalam menentukan rekomendasi } \\
\text { pemilihan burung. }\end{array}$ & $\begin{array}{l}\text { Hubungan dengan } \\
\text { penilitian ini yaitu } \\
\text { agar dapat } \\
\text { menentukan } \\
\text { pemilihan burung } \\
\text { terbaik dalam lomba } \\
\text { burung terutama } \\
\text { burung murai batu }\end{array}$ \\
\hline 3 & $\begin{array}{l}\text { (Yohanes } \\
\text { Krisdian, } \\
2015)\end{array}$ & $\begin{array}{l}\text { APLIKASI } \\
\text { LOMBA } \\
\text { BURUNG } \\
\text { BERBASIS } \\
\text { ANDROID }\end{array}$ & $\begin{array}{l}\text { Telah dirancang dan dibuat aplikasi } \\
\text { lomba burung dengan menggunakan Android } \\
\text { studio dan bahasa pemrograman java, } \\
\text { database yang digunakan adalah MySQL. } \\
\text { Untuk pengguna dibuat web untuk mendaftar } \\
\text { dan melihat hasil lomba serta informasi } \\
\text { lainnya. Setelah aplikasi dianalisis dan } \\
\text { didesain secara rinci, maka akan menuju tahap }\end{array}$ & $\begin{array}{lr}\text { Hubungan } & \text { dengan } \\
\text { penelitian ini yaitu } & \text { ingin } \\
\text { penelitian } & \text { dan } \\
\text { merancang } & \text { membangun aplikasi } \\
\text { penilaian lomba } \\
\text { burung beerbasis } \\
\text { Android terutama di }\end{array}$ \\
\hline
\end{tabular}




\begin{tabular}{|c|c|c|c|c|}
\hline No & $\begin{array}{c}\text { Nama } \\
\text { Peneliti }\end{array}$ & Judul & Hasil & $\begin{array}{c}\text { Hubungan Dengan } \\
\text { Penelitian }\end{array}$ \\
\hline & & & $\begin{array}{l}\text { implementasi. Tahap implementasi ini } \\
\text { digunakan untuk menjelaskan tentang manual } \\
\text { modul kepada pengguna, sehingga pengguna } \\
\text { dapat memberikan masukan kepada } \\
\text { pembangun agar sistem dapat dikembangkan } \\
\text { menjadi lebih baik. }\end{array}$ & $\begin{array}{l}\text { perlombaan burung } \\
\text { murai batu. }\end{array}$ \\
\hline 4 & $\begin{array}{l}\text { (Yohanes } \\
\text { Krisdian, } \\
2015 \text { ) }\end{array}$ & $\begin{array}{l}\text { Penentuan } \\
\text { Pemenang } \\
\text { Lomba Cosplay } \\
\text { Berbasis } \\
\text { Weighted } \\
\text { Product }\end{array}$ & $\begin{array}{l}\text { Aplikasi sistem ini dibuat sebagai alat bantu } \\
\text { pengambilan keputusan penentuan } \\
\text { pemenang lomba cosplay dengan } \\
\text { menggunakan metode Weighted Product. } \\
\text { Setelah pengukuran pada pretest dan posttest } \\
\text { disimpulkan bahwa sistem ini memiliki } \\
\text { tingkat keakuratan sampai dengan } 84 \% \text { untuk } \\
19 \text { data sampel yang bermasalah. }\end{array}$ & $\begin{array}{l}\text { Hubungan dengan } \\
\text { penelitian ini yaitu } \\
\text { agar perancangan } \\
\text { aplikasi yang akan } \\
\text { dibuat peneliti bisa } \\
\text { menjadi alat bantu } \\
\text { pengambilan } \\
\text { keputusan dalam } \\
\text { penentuan lomba } \\
\text { burung murai batu. }\end{array}$ \\
\hline 5 & $\begin{array}{l}\text { (Sistem } \\
\text { Pendukung } \\
\text { Keputusan } \\
\text { Penilaian } \\
\text { Kinerja } \\
\text { Karyawan } \\
\text { Menggunak } \\
\text { an Metode } \\
\text { Weighted } \\
\text { Product di } \\
\text { PT Makmur } \\
\text { Jaya } \\
\text { Kharisma, } \\
\text { 2017) }\end{array}$ & $\begin{array}{l}\text { Sistem } \\
\text { Pendukung } \\
\text { Keputusan } \\
\text { Penilaian } \\
\text { Kinerja } \\
\text { Karyawan } \\
\text { Menggunakan } \\
\text { Metode } \\
\text { Weighted } \\
\text { Product } \\
\text { di PT Makmur } \\
\text { Jaya Kharisma }\end{array}$ & $\begin{array}{l}\text { Pendekatan metode perankingan } \\
\text { WEIGHTED PRODUCT pada sistem dapat } \\
\text { diterapkan dalam kasus penilaian karyawan } \\
\text { dengan kriteria yang disesuaikan oleh } \\
\text { perusahaan. Dalam penyusunan jadwal } \\
\text { kuliah menggunakan Algoritma Genetika, } \\
\text { bila list matakuliah, banyak perulangan, dan } \\
\text { banyak individu yang digunakan berbeda, } \\
\text { maka susunan jadwal yang dihasilkan juga } \\
\text { akan berbeda - beda. }\end{array}$ & $\begin{array}{l}\text { Hubungan dengan } \\
\text { penelitian ini yaitu } \\
\text { agar perengkingan } \\
\text { pada sistem dalam } \\
\text { aplikasi dapat } \\
\text { diterapkan dengan } \\
\text { kriteria yang sudah } \\
\text { berlaku. }\end{array}$ \\
\hline
\end{tabular}

\section{Metode Penelitian}

Lokasi penelitian bertempat di Perumnas Talang Sawah Kelurahan Sukorejo Kecamatan Pagar Alam Selatan Kota Pagar Alam. Penelitian ini dilaksanakan dari bulan Desember 2019 sampai dengan Juni 2020. Instrumen penelitian adalah wawancara. Berikut pertanyaan wawancara dan Observasi

\section{Instrumen Wawancara}

Bagaimana sistem penilaian yang berjalan saat ini?

\section{Indikator}

Sistem yang berjalan saat ini masih manual juri melakukan penilaian kepada burung yang sedang kontes dengan memberikan media bendera danalat tulis sebagai penilaian.

Apa saja media yang digunakan Bendera dan alat Tulis. dalam melakukkan penilaian saat ini? 
Apa saja kendala yang terjadi pada sistem yang berjalan saat ini?
Kurangnya keefektifan dan keefisienan dalam penilaian dan lebih banyak menghabiskan waktu.

Bagaimana cara melakukan penilaian Juri menilai burung dari bunyi, stabil bunyi, volume dan ggaya pada sistem yang berjalan saat ini?

Bagaimana tanggapan para juri nanti Sangat mendukung karena dapat membantu melakukan penilaian jika dibuatnya aplikasi penilaian lomba Burung Murai Batu berbasis android

\begin{tabular}{lll}
\hline \multicolumn{2}{c}{ Instrumen Observasi } & Indikator \\
\hline $\begin{array}{l}\text { Apa saja } \\
\text { dilakukan? }\end{array}$ & penilaian yang & $\begin{array}{l}\text { Penilaian yang dilakukan oleh juri terdiri dari bunyi, stabil } \\
\text { bunyi, gaya, volume, irama, dan tembakan. }\end{array}$
\end{tabular}

Bagaimana sistem itu berjalan?

Sistem yang sedang saat ini masih secara manual dan membuat kenerja juri kurang efektif.

Apa saja kendala saat sistem itu berjalan?
Sering terjadinya kesalahan dalam penginputan nilai oleh juri.
Apa saja data yang didapatkan dalam observasi?
Mengetahui sistem yang sedang berjalan saat ini, mengetahuhi penilaian yang dilakukan oleh juri, dan mengetahui kekurang sistem yang sedang berjalan.

Kuesinoner ini juga akan di berikan juga pada saat Expert Review (Uji para ahli) untuk melihat ke validan aplikasi animasi pembelajaran yang akan di buat. Menurut Tessmer untuk mengujikan validitas produk kepada Expert Review dibagi menjadi 4 bagian yaitu ahli desain, ahli materi, ahli bahasa, serta ahli media. Kisi-kisi kuesioner Expert Review dapat dilihat pada table berikut:

\begin{tabular}{|c|c|c|c|c|}
\hline NO. & Topik & & Indikator & \\
\hline \multirow[t]{3}{*}{1.} & Design & (Aplikasi & \multirow{3}{*}{$\begin{array}{l}\text { 1. Kejelasan tujuan aplikasi penilaian (standar } \\
\text { kompetensi dasar dan indikator). } \\
\text { 2. Kelengkapan Materi }\end{array}$} & \multirow{3}{*}{ kompetensi, } \\
\hline & Penilaian Lomba & Burung & & \\
\hline & Murai & Berbasis & & \\
\hline
\end{tabular}




\begin{tabular}{|c|c|c|}
\hline & Android). & $\begin{array}{l}\text { 3. Ketepatan Animasi } \\
\text { 4. Penggunaan Bahasa } \\
\text { 5. Sistematika Penyajian Materi } \\
\text { 6. Kualitas Tampilan } \\
\text { 7. Katepatan Pewarnaan }\end{array}$ \\
\hline 2. & $\begin{array}{lrr}\text { Ahli Materi } & \text { pada(Aplikasi } \\
\text { Penilaian Lomba } & \text { Burung } \\
\text { Murai } & \text { Batu } & \text { Berbasis } \\
\text { Android). } & & \\
\end{array}$ & $\begin{array}{l}\text { 1. Relevansi isi aplikasi dengan tujuan perlombaan. } \\
\text { 2. Kualitas materi/menu pada Aplikasi Penilaian Lomba Burung } \\
\text { Murai Batu Berbasis Android. }\end{array}$ \\
\hline 3. & Ahli Bahasa & $\begin{array}{l}\text { 1. Kesesuaian dengan ejaan bahasa Indonesia. } \\
\text { 2. Struktur Kalimat } \\
\text { 3. Struktur Kata }\end{array}$ \\
\hline 4. & Ahli Media & $\begin{array}{l}\text { 1. Kemudahan dalam penggunaan Aplikasi Penilaian Lomba } \\
\text { Burung Murai Batu Berbasis Android. } \\
\text { 2. Kesesuaian pengguna Aplikasi Penilaian Lomba Burung Murai } \\
\text { Batu Berbasis Android. } \\
\text { 3. Kesesuaian media dalam lingkungan perlombaan kicau burung. } \\
\text { 4. Kesesuaian pengguna Aplikasi Penilaian Lomba Burung Murai } \\
\text { Batu Berbasis Android dengan Perlombaan Burung Murai Batu. } \\
\text { 5. Kesesuaian Aplikasi Penilaian Lomba Burung Murai Batu } \\
\text { Berbasis Android dengan kemampuan para juri tentang } \\
\text { pemahaman kemajuan teknologi. } \\
\text { 6. Keakuratan isi Aplikasi Penilaian Lomba Burung Murai Batu. }\end{array}$ \\
\hline
\end{tabular}

\section{Hasil dan Pembahasan}

Hasil rekapitulasi diatas dihasilkan setelah mendapatkan saran dari validator. Dari hasil validator tersebut telah dilakukan perbaikan menjadikan produk menjadi valid. Validator memberikan kementar pada kolom yang disediakan pada kuisioner mengenai Aplikasi Penilaian Lomba Burung Murai Batu berbasis Android dan juga dapat memberikan saran secara deskriptif kepada penulis untuk kejelasan perbaikan untuk mencapai produk layak digunakan hingga mencapai produk yang valid. Maka berdasarkan hasil kuesiner tersebut didapatkan hasil pada uji bahasa didapatkan skor rata-rata 3,80 dengan kriteria valid dan uji desain mendapatkan skor 3,60 dengan kriteria valid, kemudian uji materi didapatkan skor 4 dengan kriteria sangat valid Selanjutnya dan uji media mendapatkan skor 4,25 sehingga hasil rata-rata 3,9 dengan kategori sangat valid. Hal ini menunjukan Aplikasi Penilaian Lomba Burung Murai Batu berbasis Android sudah menunjukan produk yang valid. 


\section{HASIL REKAPITULASI SKOR ANGKET VALIDITAS}
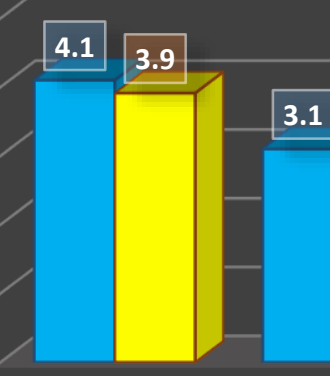

Sangat Valid

Valid

Cukup Valid
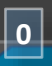

Adapun tampilan menu-menu pada Aplikasi Penilaian Lomba Burung Murai Batu berbasis Android adalah sebagai berikut:

\section{Tampilan Icon Aplikasi}

Pada Icon Aplikasi merupakan tampilan awal pada android untuk masuk ke aplikasi android.

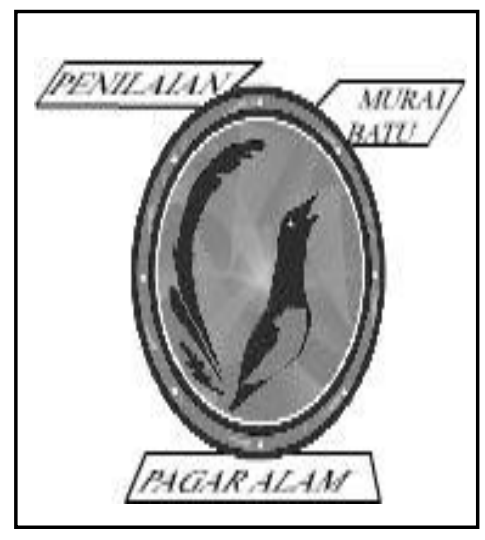

Sebelum

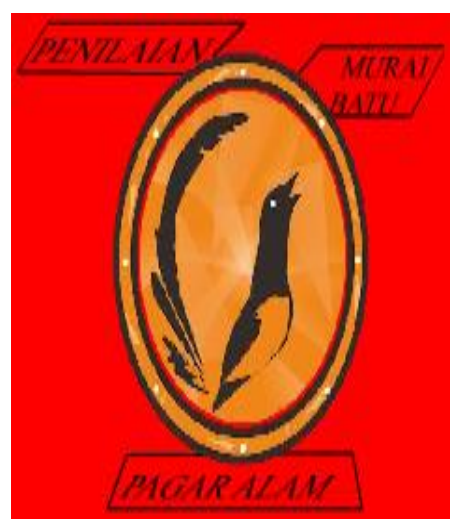

Sesudah

\section{Tampilan Splash Screen}

Pada gambar kedua merupakan tampilan yang muncul saat pertama kali kita membuka sebuah aplikasi atau tampilan pembuka sebelum masuk ke tampilan menu utama. 


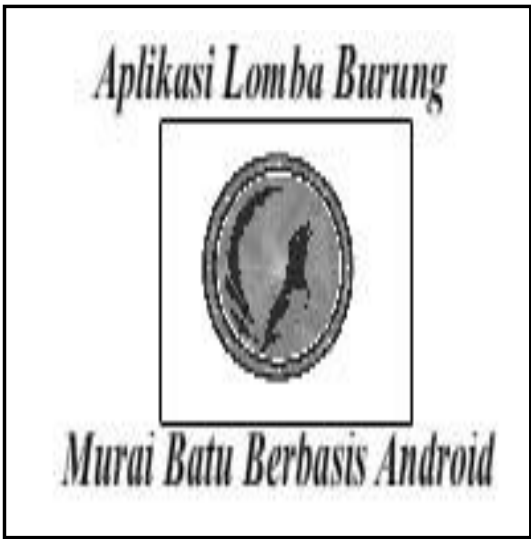

Sebelum

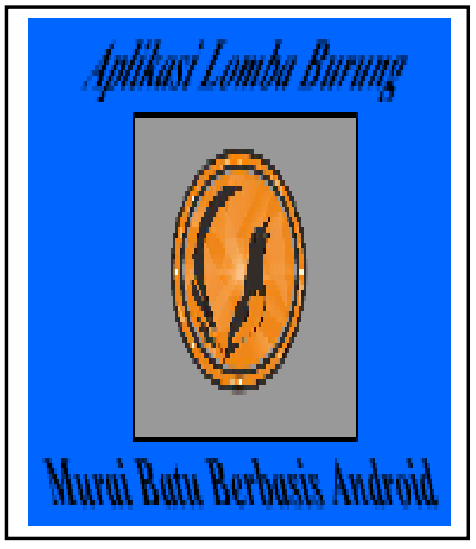

Sesudah

Menu utama berisi menu-menu utama yaitu menu nomor gantangan, menu petunjuk, dan menu keluar untuk keluar dari aplikasi.
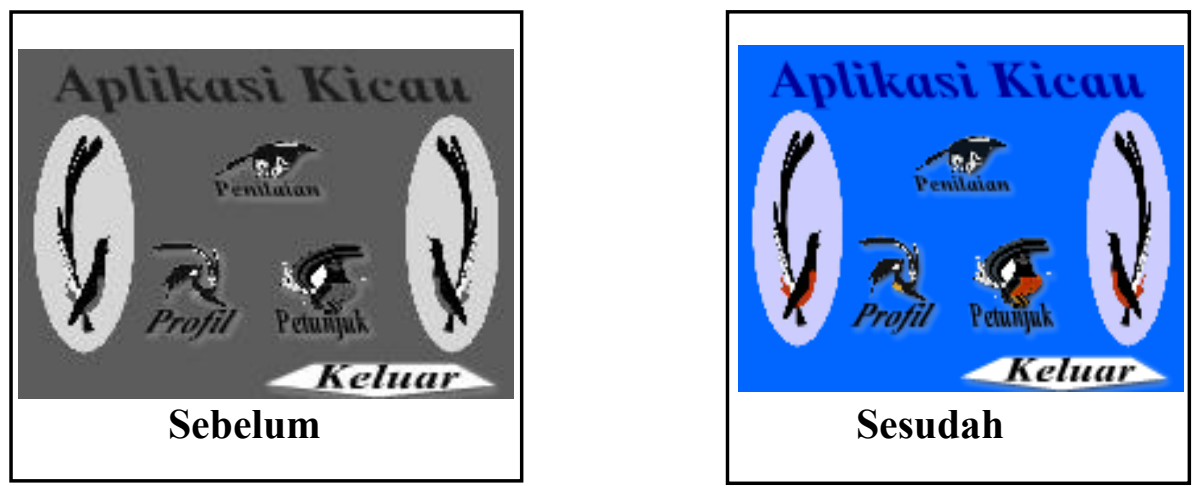

\section{Menu Nomor Gantangan}

Pada Menu nomor gantangan user akan di hadapkan dengan pilihan menu yaitu menu dengan nomor gantangan yang telah ditentukan untuk melakukan penilian dalam perlombaan kicau burung. 


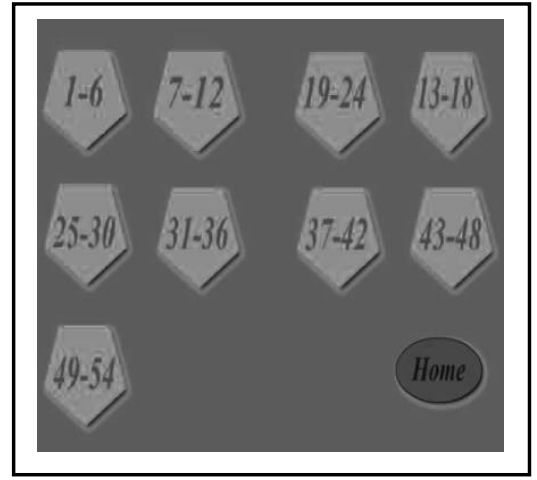

Sebelum

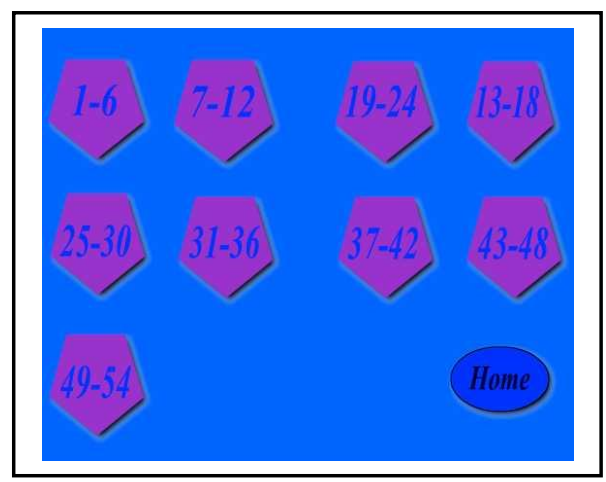

Sesudah

\section{Menu Petunjuk}

Menu cara penggunaan berisi tentang bagaiamana cara menggunakan aplikasi tersebut.

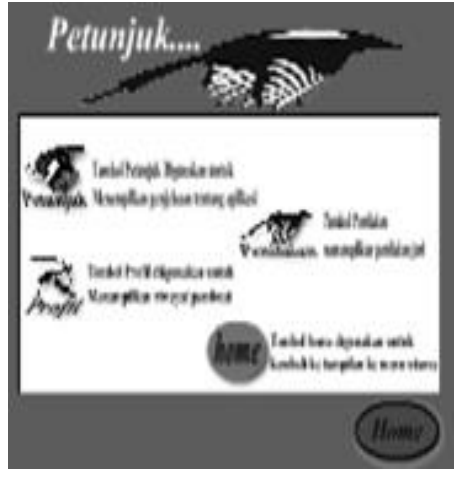

Sebelum

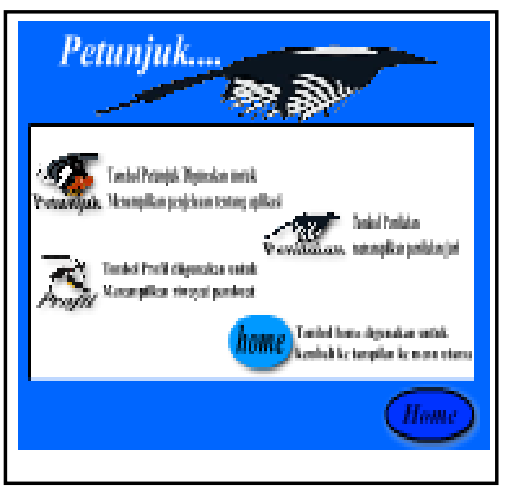

Sesudah

\section{Menu Petunjuk Dalam Penilaian}

Menu petunjuk dalam penilaian berisi informasi tentang tombol-tombol dalam menu penilaian yang memberikan petunjuk berapa nilai yang akan diberikan oleh juri pada saat menggunakan tombol-tombol yang akan digunakan.

\section{Sebelum}

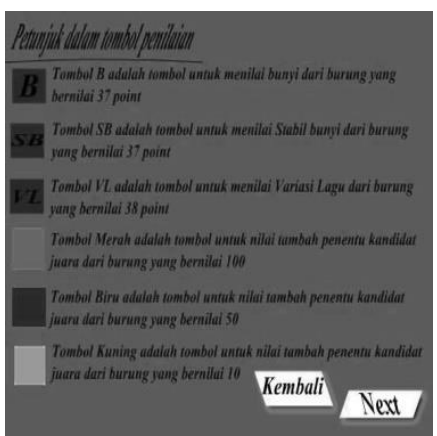

Sesudah

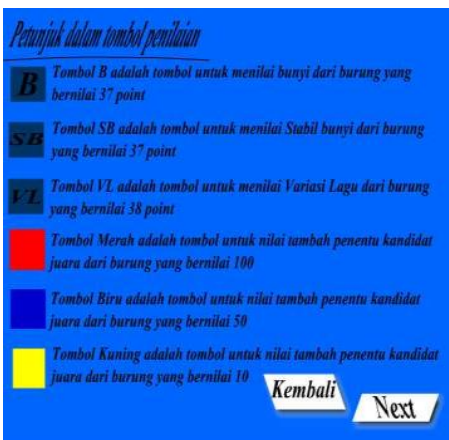




\section{Menu Penilaian}

Menu penilaian berisi tempat untuk para juri melakukan penilaian. Pada menu ini terbagi 6 (enam) kotak nomor gantangan yang terdiri dari setiap kotak memiliki 4(empat) warna dan 6 (enam) tombol untuk menginputkan nilai yang masingmasing warna telah di tetapkan nilainya, seperti Warna Kuning(10), Biru(50), Merah(100), B (37), SB(37) VL(38). Jadi juri hanya menekan tombol warna tersebut untuk melakukan penilaian sesuai dengan durasi suara burung, gaya, irama, dan tembakan.

Sebelum

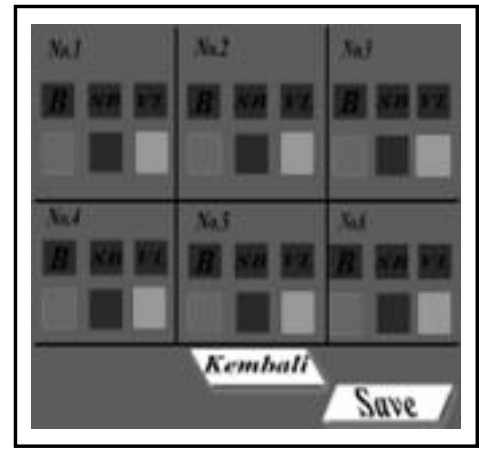

Sesudah

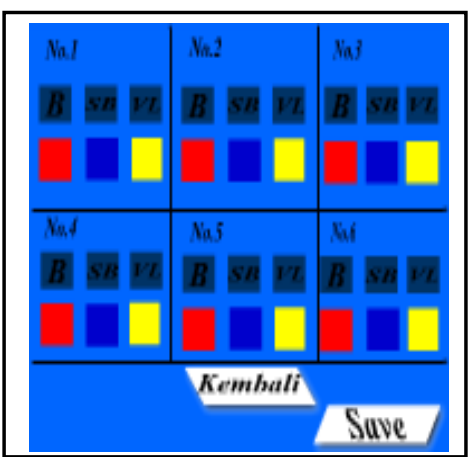

\section{Menu Hasil Penilaian}

Menu hasil penilaian berisi tampilan hasil dari nilai yang telah di inputkan oleh juri.

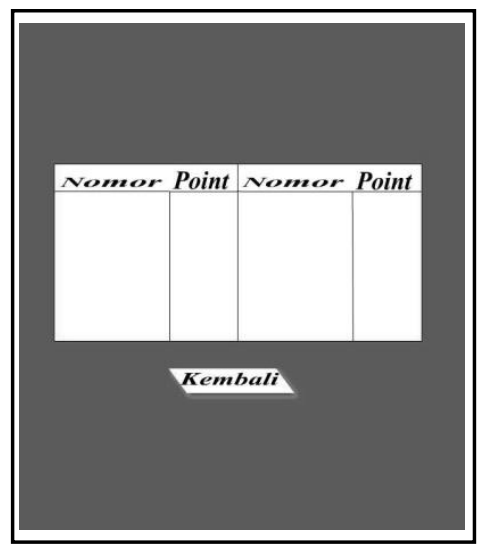

Sebelum

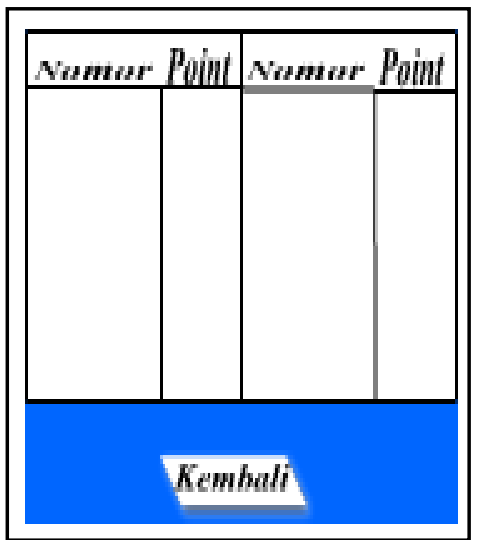

Sesudah 


\section{Menu Profil}

Menu profil yang berisi profil pembuat aplikasi disertai dengan foto agar user mengetahui siapa pembuat dari aplikasi penilaian ini.

Sebelum

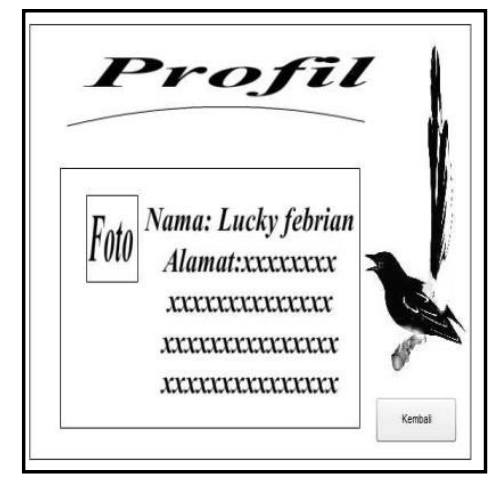

Sesudah

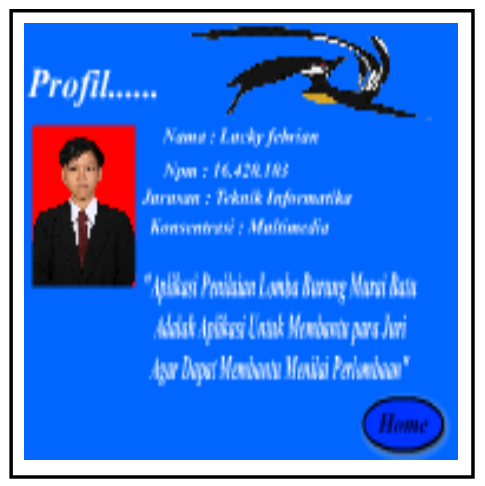

\section{Menu Halaman Web Home}

Pada menu halaman web home ini berisi menu login, data hasil penilaian dan foto kegiatan perlombaan burung murai batu.

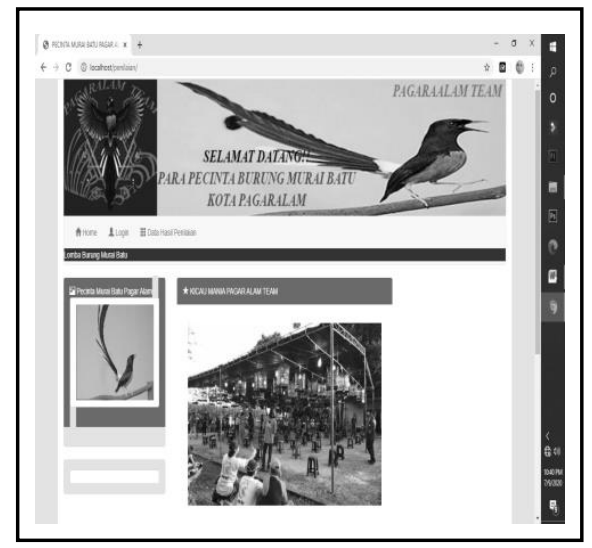

Sebelum

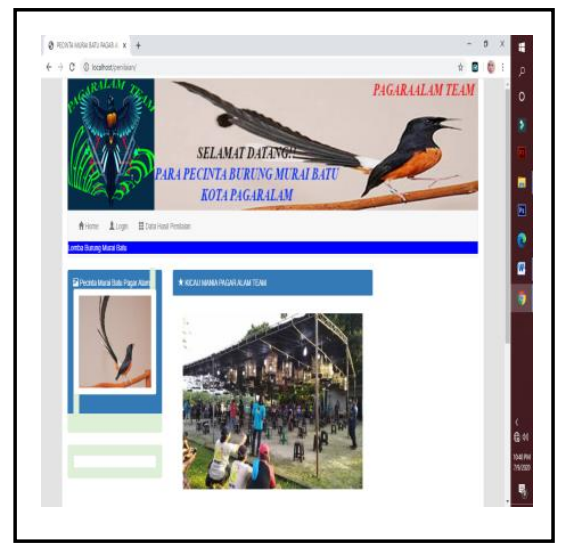

Sesudah

\section{Menu Halaman Login Web}

Menu login berisi menu untuk admin masuk ke halaman berikutnya untuk melakukan penginputan nilai, dengan memasukkan username dan password. 


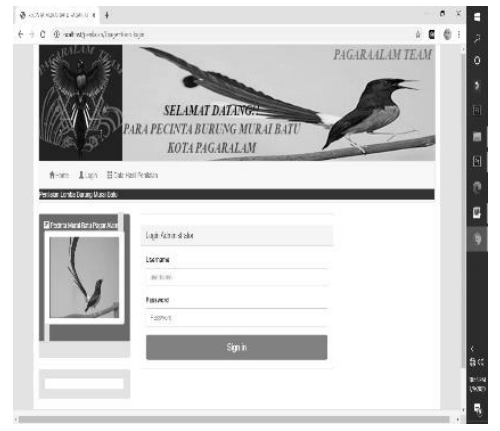

Sebelum

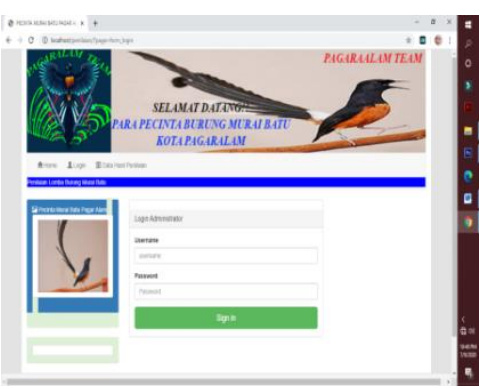

Sesudah

\section{Menu Halaman Admin Web}

Menu halaman web terdapat menu beranda, hasil penilaian, user dan logout.

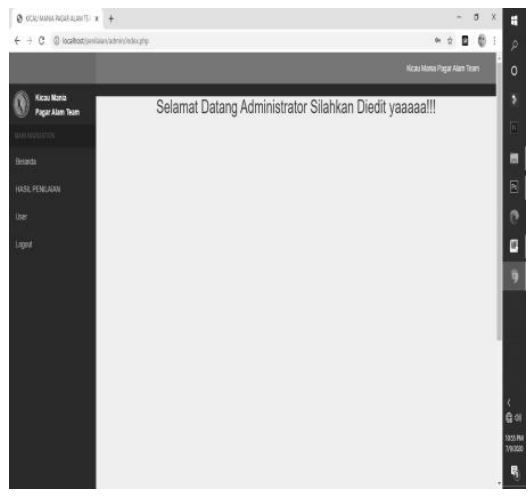

Sebelum

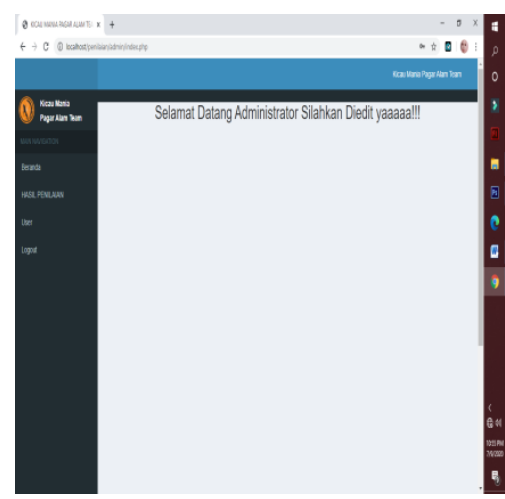

Sesudah

\section{Menu Halaman Input Penilaian Admin}

Pada menu ini admin akan menginputkan hasil penilaian juri dari perlombaan yang telah berlangsung.

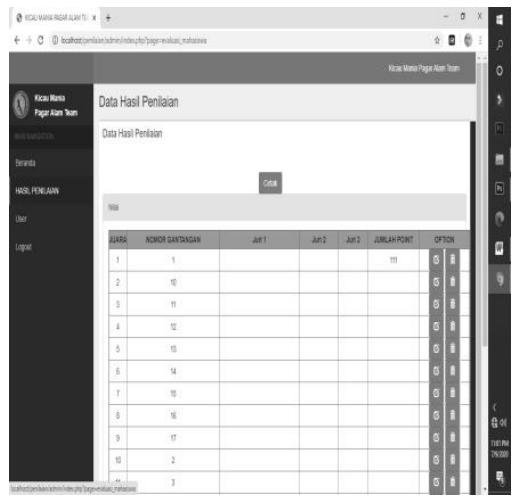

Sebelum

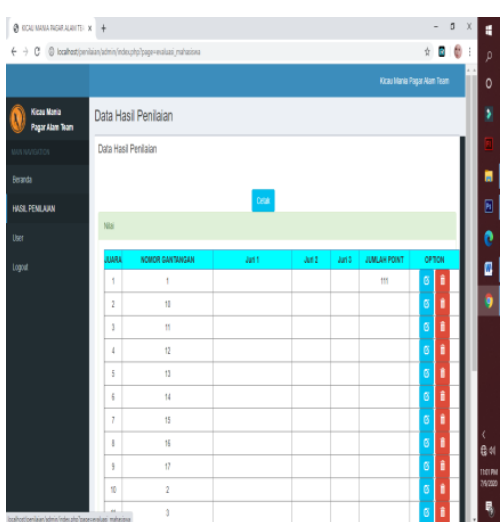

Sesudah 


\section{Menu Halaman Data Hasil Penilaian}

Pada halaman ini peserta dapat melihat hasil dari rekap penilaian yang telah di lakukan oleh admin berdasarkan hasil penilaian para juri selama lomba berlangsung.

Sebelum

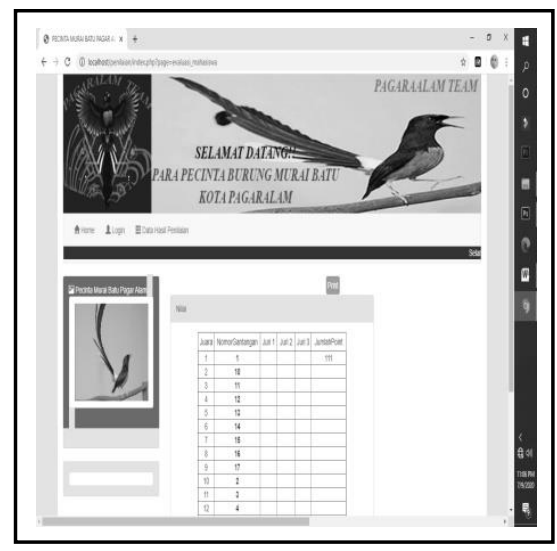

\section{Sesudah}

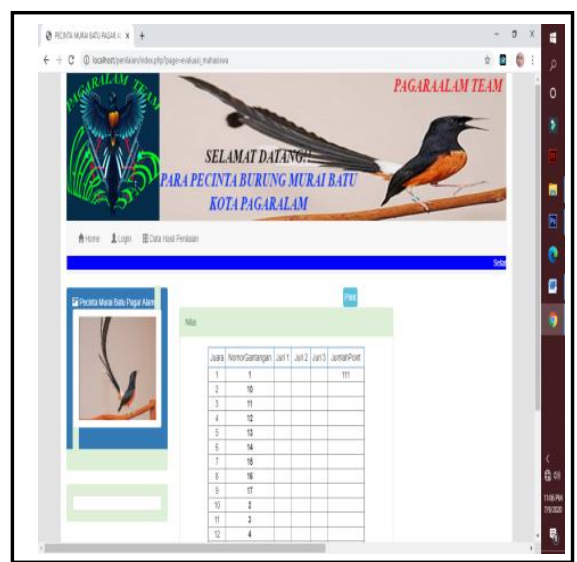

\section{Menu Halaman Cetak Sertifikat}

Pada halaman ini berisi untuk mencetak sertifikat untuk burung yang mendapatkan juara/rangking.

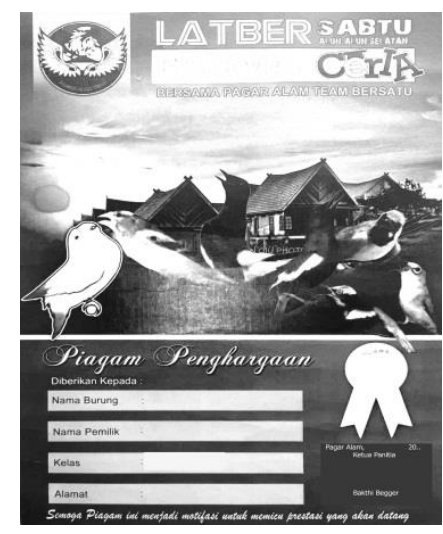

Sebelum

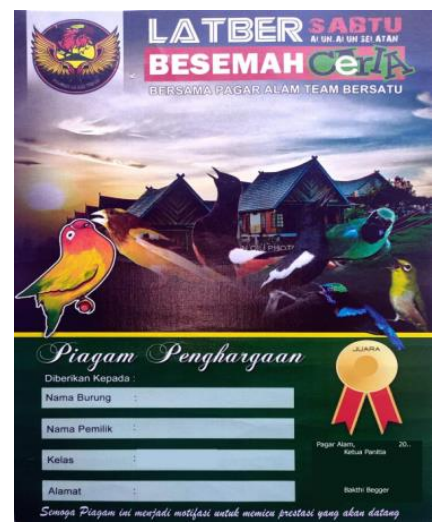

Sesudah 


\section{Kesimpulan}

Berdasarkan seluruh hasil tahapan yang telah dilakukan pada Aplikasi Penilaian Lomba Burung Murai Batu Berbasis Android di Pagar Alam Team dapat Disimpulkan:

Dalam penelitian ini telah menghasilkan Aplikasi Penilaian Lomba Burung Murai Batu berbasis Android pada program studi Teknik Informatika Sekolah Tinggi Teknologi Pagar Alam. Aplikasi Penilaian Lomba Burung Murai Batu berbasis Android menggunakan aplikasi Adobe Flash Professional CS6 dan Database MySql. Aplikasi Penilaian Lomba Burung Murai Batu berbasis Android di Pagar Alam Team dinyatakan valid. Data diperoleh dari komentar dan saran pada lembar validasi yang diberikan oleh ahli bahasa, ahli materi, ahli media, dan ahli desain. Aplikasi Penilaian Lomba Burung Murai Batu berbasis Android ini memiliki kriteria valid ditinjau dari aspek isi/ materi, aspek penggunaan bahasa, aspek kelengkapan format dalam penilaian, dan aspek desain, Hasil validasi ahli Bahasa menunjukkan bahwa Aplikasi Penilaian Lomba Burung Murai Batu berbasis Android ini mempunyai kriteria sangat baik dengan ratarata skor 3,8 sedangkan hasil validasi ahli materi menunjukkan bahwa Aplikasi Penilaian Lomba Burung Murai Batu berbasis Android ini sangat baik dengan rata-rata skor 4 dan hasil validasi ahli desain menunjukkan bahwa Aplikasi Penilaian Lomba Burung Murai Batu berbasis Android ini sangat baik dengan rata-rata skor 3,6 kemudian validasi ahli media menunjukan bahwa aplikasi penilaian ini baik dengan rata-rata 4,25 dengan kriteria sangat valid dengan hasil rata-rata 3,9 dengan kategori sangat valid.

\section{Referensi}

Andriansyah, W., Fernando, E., \& Sadikin, A. (2017). Perancangan Aplikasi Pengenalan Alat Musik Tradisional Nusantara Berbasis Android. PROCESSOR, 1011 - 1020 .

Adithya Marhaendra Kusuma, E. Y. (2016). APLIKASI BUKU DIGITAL BIDANG TEKNOLOGI INFORMASI. JURNAL KOMUNIKASI, MEDIA DAN INFORMATIKA, 2.

Adithya Marhaendra Kusuma, E. Y. (2016). APLIKASI BUKU DIGITAL BIDANG TEKNOLOGI INFORMASI BERBASIS ANDROID MOBILE PADA PERPUSTAKAAN BPPKI SURABAYA BADAN LITBANG KEMENTERIAN KOMINFO. JURNAL KOMUNIKASI, MEDIA DAN INFORMATIKA, 2.

Amirullah, G., \& susilo. (2018). Pengembangan Media Pembelajaran Interaktif Pada Konsep Monera Berbasis Smartphone Android. 38-45.

DELFI ANDRE, E. P. (2011). SMARTPHONE SEBAGAI GAYA HIDUP (Studi Deskriptif Tentang Penggunaan Smartphone Sebagai Gaya Hidup Mahasiswa FISIP USU). 2.

Eka Larasati Amalia, R. A. (2019). Sistem Pendukung Keputusan Menentukan Lovebird Unggul dalam Perlombaan Menggunakan Metode AHP-Topsis . Jurnal Ilmu Komputer dan teknologi Informasi, 1.

Firmantoro, K., Anton, \& Nainggolan, E. R. (2016). ANIMASI INTERAKTIF PENGENALAN HEWAN UNTUK PENDIDIKAN ANAK USIA DINI . Jurnal TECHNO Nusa Mandiri, 103-110.

iswari, n. m. (2015). review perangkat lunak staruml berdasarkan faktor kualitas mccall. 20854552 .

KOMPUTER, W. (2012). SHORTCOURSE SERIES ADOBE PHOTOSHOP CS6. Semarang: Andi. 
Komputer, W. (2013). Adobe Dreamweaver CS6. Semarang: Andi.

Kurniawan, A. (2018). SISTEM PENDUKUNG KEPUTUSAN PENILAIAN KONTES BURUNG CENDET MENGGUNAKAN ALGORITMA PROFILE MATCHING DI EO NIRWANA BC. Artikel Skripsi Universitas Nusantara PGRI Kediri, 3 dan 8.

Lestari, A. S. (2013). PEMBELAJARAN MULTIMEDIA . Jurnal Al-Ta'dib , 2-3.

Linda, D. (2016 ). Merancang e-katalog Berbasis Web Sebagai Media Informasi Pada Badan Perpustakaan Arsip dan Dokumentasi Daerah (BPAD) Lampung. Jurnal Sistem Informasi \& Telematika, 1-11.

Madcoms. (2012). Adobe Flash Prefesional CS6 untuk Pemula. yogyakarta: andi offset.

Madcoms. (2016). PEMROGRAMAN PHP dan MYSQL untuk pemula. Yogyakarta: ANDI OFFSET.

Maiyana, E. (2018). PEMANFAATAN ANDROID DALAM PERANCANGAN APLIKASI KUMPULAN DOA . JURNAL SAINS DAN INFORMATIKA, 4.

MARIFA, I. E. (2014). TEKNIK PENGELOLAAN DAN PENILAIAN KESEJAHTERAAN MURAI BATU (Copsychus malabaricus Scopoli, 1788) DI MEGA BIRD AND ORCHID FARM, BOGOR, JAWA BARAT. INSTITUT PERTANIAN BOGOR, 13.

Murtiwiyati, \& Lauren, G. (2013 ). Rancang Bangun Aplikasi Pembelajaran Budaya Indonesia Untuk Anak Sekolah Dasar Berbasis Android. Jurnal Ilmiah KOMPUTASI, 1-10.

Musyawarah, R. (2005). Membangun Aplikasi Batabase Berbasis Web Untuk Pemula . Jakarta: PT. Elex Media Komputindo.

Putrawansyah, F. (2017). Aplikasi Computer Assisted Test (CAT) Pada Penerimaan Mahasiswa Baru Sekolah Tinggi Teknologi Pagar Alam (STTP). Jurnal RESTI, 1-8.

Putrawansyah, F. (2017). Aplikasi Computer Assisted Test (CAT) Pada Penerimaan Mahasiswa Baru Sekolah Tinggi Teknologi Pagar Alam (STTP). JURNAL RESTI (Rekayasa Sistem dan Teknologi Informasi), 1-8.

Rahmad, M. B., \& Setiady, T. (2014). Perancangan SIstem Informasi Inventory Spare Part Elektronik Berbasis web PHP (Studi CV.Human Global Service Yogyakarta). Jurnal Sarjana Teknik Informatika, 131-139.

Rizal Rudiantoro, I. C. (2019). Rekomendasi Pemilihan Burung Menggunakan Metode Simple Additive Weighting (SAW) dan Technique Order Preference by Similarity To Ideal Solution (TOPSIS). Jurnal Pengembangan Teknologi Informasi dan Ilmu Komputer, 5.

Rojali Soni Afandi, E. H. (2013). APLIKASI MOBILE INFORMASI KAFE 24 JAM DI YOGYAKARTA BERBASIS ANDROID. Jurnal Ilmiah DASI, 1-5.

Rossa A.S, M. (2014). Rekayasa Perangkat Lunak. Bandung: Informatika Bandung.

Safaat, N. (2014). Android PemrogramanAplikasi Mobile Smartphone dan Tablet Pc Berbasis Android. Bandung: INFORMATIKA.

Safaat, N. (2016). Android pemograman Aplikasi Mobile Smartphone dan Tablet PC Berbasis Android. jurnal sains dan teknologi , 7-8.

Sari, D. M. (2014). kamus obat bebas berbasis android . 1. 
Sitorus, R. (2017). Aplikasi Pembelajaran Struktur Data Berbasis Android Menggunakan Metode Computer Based Instruction (Cbi). jurnal PIBD, 99-104.

Sujana, F. R. (2016). ANALISIS STUDI KELAYAKAN BISNIS PENANGKARAN BURUNG MURAI BATU SUMATRA. SNKIB, 167.

Sukrisna, D., \& Jubaedi, D. (2018). Pengembangan Bahan Ajar Animasi INteraktif 2D Berbasis Android Pada Mata Kuliah Fisika Dasar I Materi Fluida. Jurnal Sains dan Teknologi, 1-10.

Suyanto, M. (2003). MULTIMEDIA alat untuk meningkatkan keunggulan bersaing. Yogyakarta: ANDI OFFSET.

Ugiarto, M., Cahyono, B., \& R, R. H. (2017). Media Pembelajaran Mata Kuliah Komputer Animasi Berbasis Android Di Fakultas Ilmu Komputer Dan Teknologi Informasi Universitas Mulawarman Samarinda. Jurnal Teknologi Informasi, 315-320.

Umar, N., \& Nasir, M. k. (2016). Perancangan Aplikasi Media Pembelajaran Drum Berbasis Android. Jurnal Informatika, 622-627.

Widodo, M. R., Zainuddin, M. R., \& Nusantara, L. S. (2016). SISTEM INFORMASI DAN PENGOLAHAN DATA KURSUS MOBIL BERBASIS WEB DENGAN SMS GATEWAY DI ARMADA PASURUAN. Jurnal Informatika Merdeka Pasuruan, 85-104.

Yohanes Krisdian, E. C. (2015). Aplikasi Lomba Burung Berbasis Android. Jurnal Ilmiah Go Infotech, 4.

\section{Copyrights}

Copyright for this article is retained by the author(s), with first publication rights granted to the journal.

This is an open-access article distributed under the terms and conditions of the Creative Commons Attribution license (http://creativecommons.org/licenses/by/4.0/) 